\title{
CYTOLOGY IN PREVENTION OF CANCER OF CERVIX
}

BY

\author{
MARIE P. S. GRANT, M.B., Ch.B., M.R.C.O.G. \\ Senior Medical Officer (M. \& C.W.), Fife County Council
}

The value of cytology has been but grudgingly admitted in this country during the past ten years, and although recently its use, particularly in the gynaecological field, has extended, only a small minority of all gynaecological and post-natal patients have the advantage of cytology as part of their routine examination.

I had the opportunity to join the cytological service started in Edinburgh by Dr. A. F. Anderson, at the request of Professor Kellar, in 1949, and the advantage of routine cytology in gynaecological practice soon became apparent (Anderson et al., 1951, 1953).

In 1955 Professor Ian Donald, of Glasgow University, asked for a cytological service for his patients at the Western Infirmary, and this was started for a trial period, with the permission and co-operation of the medical officer of health, Dr. W. A. Horne, who offered laboratory facilities and technical help for the staining of the smears. The time available for cytology was limited and the service could not cover all the patients attending the unit, so it was arranged that those over 40 years of age should be screened routinely and as many of those under 40 as possible. Cervical scrape smears were taken as advocated by Ayre (1947), and these were fixed and stained by the Papanicolaou method (Papanicolaou and Traut, 1943).

\section{Results}

The number of slides received in the laboratory was 3,682 , but the results are based on the first smear received from each patient (Table I). This group of 3,366 patients included 35 who had an obvious cervical cancer when seen for the first time in the out-patient department (Table II), and a group of 275 patients who were suspected of having cervical cancer and who provided five cancers. The remaining 3,056 patients were regarded as having benign cervices and yielded 35 cancers, giving an overall incidence of unsuspected cancer of $1.04 \%$.

\section{TABLE I}

Total number of smears received

Total number of smears received
Repeat and follow-up smears

Unsatisfactory smears

Number of patients screened

$\ldots$
$\cdots$
$\cdots$

\section{3,682
292
24 \\ 3,366}

TABLE II

\begin{tabular}{|c|c|c|c|c|}
\hline \multicolumn{2}{|c|}{ Cancers Found } & Invasive & In Situ & Total \\
\hline $\begin{array}{l}\text { Clinically obvious } \\
\text { Suspected } \\
\text { Unsuspected }\end{array}$ & $\begin{array}{l}\cdots \\
\cdots \\
\cdots\end{array}$ & $\begin{array}{r}35 \\
2 \\
7\end{array}$ & $\begin{array}{r}0 \\
3 \\
28\end{array}$ & $\begin{array}{r}35 \\
5 \\
35\end{array}$ \\
\hline Total & . & 44 & 31 & 75 \\
\hline
\end{tabular}

Of the 35 patients with unsuspected cancer, 17 were discovered solely because of the cytological screening. Of these 17 patients, 5 (one of whom had an obvious invasive cancer histologically) were regarded as gynaecologically normal and requiring no treatment, and the other 12 were to receive no investigation or treatment of the cervix but were put on the waiting-list for other reasons-for example, cauterization of a urethral caruncle.

The remaining 18 of the 35 patients with unsuspected cancer would probably have been found later by histological examination of the cervix following hysterectomy, amputation of the cervix during repair operations, and conization for the treatment of erosions. Six of these cancers, however, were already invasive and one would only have had an amputation of cervix during a repair as there was no macroscopic evidence of malignancy.

Thus, apart from finding the purely unsuspected cancer, cytology is of advantage to the patient in that (1) unsuitable treatment may be prevented-for example, amputation of the cervix for invasive cancer ; and (2) even if the patient is on the waiting-list for investigation, waiting-time is eliminated for all those with suspicious cytology.

\section{Errors}

False Negative.-One patient with a negative smear had a biopsy on clinical grounds, and was found to have an invasive cancer. The smear was rechecked and no suspicious cells could be seen, so it must be assumed that the spatula did not touch the affected area.

False Positive.-There were no false positives.

Sub Judice (4).-One patient has refused investigation although her smear showed definite evidence of malignancy. The other three patients have had biopsies, but, unfortunately, in all three the surface epithelium had been wiped off before reaching the laboratory and there was no squamous epithelium on which to give an opinion.

Abnormal epithelium - that is, that of in-situ canceris much more easily detached from the underlying tissue than is normal squamous epithelium; the clinician should be aware of this and be prepared to take care in the immediate pre-operative preparation of the patient with positive cytology. The fact that the surface has been denuded of epithelium is in itself suspicious, and thorough sectioning of the biopsy specimen should be undertaken in these cases where, despite positive cytology, the source of abnormal cells is not apparent in the first one or two sections of the block. That only three patients required this attention out of 3,366 out-patients would not seem to impose an undue strain on any pathology department.

\section{Age Incidence}

The 35 patients with obvious clinical cancers, although of course cytology played no part in their diagnosis and smears were taken merely for interest, have been retained in the series for the purpose of comparing their age and parity with those of the patients with in-situ cancers.

The average age of the 31 patients with in-situ cancer was 40.0 years, with a range of 22 to 67 . That of the 44 patients with invasive cancer was 55.5 years, with a range of 31 to 79 . As almost all the in-situ cancers in this series were in the 35-44 age-group, the ages of all the patients were checked to determine the number in each five-year group and the number of cancers among them. The information is shown in Table III. The ages for 35 patients were not available, and so the total number in the table is 3,331 instead of 3,366 . 
Patients aged 44 and under numbered 1,623 and there were $28(1.72 \%)$ in-situ cancers among them. Those of 45 and over numbered 1,708 , but provided only 3 $(0.17 \%)$ of the in-situ cancers, although all $7(0.41 \%)$ of the unsuspected invasive cancers and, as to be expected, the majority of the obvious clinical cancers were in this group.

\begin{tabular}{|c|c|c|c|c|c|c|}
\hline \multicolumn{3}{|c|}{ Age-group } & \multirow{2}{*}{$\begin{array}{c}\begin{array}{c}\text { No. of } \\
\text { Patients }\end{array} \\
17 \\
39 \\
321 \\
616 \\
630\end{array}$} & \multirow{2}{*}{$\begin{array}{l}\begin{array}{l}\text { In-situ } \\
\text { Cancer }\end{array} \\
1 \\
0 \\
3 \\
13 \\
11\end{array}$} & \multirow{2}{*}{$\begin{array}{l}\begin{array}{c}\text { Unsuspected } \\
\text { Invasive } \\
\text { Cancer }\end{array} \\
0 \\
0 \\
0 \\
0 \\
0\end{array}$} & \multirow{2}{*}{ 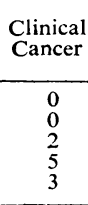 } \\
\hline $\begin{array}{l}20-24 \\
25-29 \\
30-34 \\
35-39 \\
40-44\end{array}$ & $\begin{array}{l}\cdots \\
\cdots \\
\cdots \\
\ldots\end{array}$ & $\begin{array}{l}. \\
\cdots \\
\therefore \\
.\end{array}$ & & & & \\
\hline \multicolumn{3}{|c|}{ Total under 45} & 1,623 & $28(1.72 \%)$ & 0 & 10 \\
\hline $\begin{array}{l}45-49 \\
50-54 \\
55-59 \\
60-64 \\
65-69 \\
70+\end{array}$ & $\begin{array}{l}\ldots \\
\cdots \\
\cdots \\
\cdots \\
\cdots\end{array}$ & $\begin{array}{l}. \\
\therefore \\
\therefore \\
\therefore \\
\therefore\end{array}$ & $\begin{array}{r}595 \\
402 \\
256 \\
211 \\
151 \\
93\end{array}$ & $\begin{array}{l}1 \\
1 \\
0 \\
0 \\
1 \\
0\end{array}$ & $\begin{array}{l}1 \\
2 \\
0 \\
1 \\
3 \\
0\end{array}$ & $\begin{array}{l}4 \\
5 \\
5 \\
4 \\
2 \\
7\end{array}$ \\
\hline \multicolumn{3}{|c|}{ Total over 45} & 1,708 & $3(0 \cdot 17 \%)$ & $7(0.41 \%)$ & 27 \\
\hline \multicolumn{3}{|c|}{ Total all patients } & 3,331 & 31 & 7 & 73 \\
\hline
\end{tabular}

\section{Parity}

An impression seems to have arisen that the likelihood of cancer increases with parity, and it has even been suggested that a cytological programme should be confined to those of para 4 and over. The parity of the 75 cancer patients in this series is shown in Table IV, and, bearing in mind that there are more invasive than in-situ cancers in the group, the findings are remarkably similar. There were 44 patients with a parity of $0-3$, and 31 of para 4 and over.

\begin{tabular}{|c|c|c|c|}
\hline Parity & In-situ Cancer & Invasive Cancer & Total \\
\hline $\begin{array}{l}0 \\
1 \\
2 \\
3\end{array}$ & $\begin{array}{l}0 \\
7 \\
9 \\
4\end{array}$ & $\begin{array}{r}3 \\
6 \\
11 \\
4\end{array}$ & $\left.\begin{array}{r}3 \\
13 \\
20 \\
8\end{array}\right\} 44$ \\
\hline $\begin{array}{c}4 \\
5 \\
6 \\
7 \\
8 \\
9 \\
10+\end{array}$ & $\begin{array}{l}7 \\
3 \\
0 \\
0 \\
0 \\
1 \\
0\end{array}$ & $\begin{array}{l}8 \\
4 \\
2 \\
0 \\
0 \\
2 \\
4\end{array}$ & $\left.\begin{array}{r}15 \\
7 \\
2 \\
0 \\
0 \\
3 \\
4\end{array}\right\} 31$ \\
\hline Total & 31 & 44 & 75 \\
\hline
\end{tabular}

\section{Cervical Erosion}

Another impression is that early cancer is more likely to be found in the eroded cervix, and so the information available was examined in detail to determine whether any conclusions could be drawn and to discover what types of cervices had been screened. The request form which is used for cytological examination requires, in addition to other information, a description of the cervix. Printed on the form under "Description of Cervix" is "Intact Epithelium, Benign, Eroded, Suspicious, and Malignant," so that the clinician only needs to underline what is appropriate for each patient. Other comments may of course be added as desired. Many descriptions were given on the forms in which both intact epithelium and benign, or eroded and benign, were underlined, and in these cases the patient was included in the appropriate intact epithelium or eroded group. When the cervix was described as eroded and suspicious it was included with the other cervices described as suspicious. Occasionally the word benign only was underlined and no other information given.

This information was used as a basis for assessment of clinical suspicion, and the results are shown in Table V.

\begin{tabular}{|c|c|c|c|c|}
\hline \multirow{2}{*}{ Appearance of Cervix } & \multirow{2}{*}{$\begin{array}{c}\text { No. of } \\
\text { Patients }\end{array}$} & \multicolumn{3}{|c|}{ No. of Cancers } \\
\hline & & In Situ & Invasive & Total \\
\hline $\begin{array}{l}\text { Intact epithelium } \\
\text { Benign (.. } \\
\text { Eroded (benign) } \\
\text { Suspicious } \\
\text { Malignant }\end{array}$ & $\begin{array}{r}1,499 \\
163 \\
1,389 \\
275 \\
40\end{array}$ & $\begin{array}{r}12 \\
1 \\
15 \\
3 \\
0\end{array}$ & $\begin{array}{r}6 \\
0 \\
1 \\
2 \\
35\end{array}$ & $\begin{array}{l}18(1 \cdot 2 \%) \\
1 \\
16(1 \cdot 15 \%) \\
5 \\
35\end{array}$ \\
\hline Total ... & 3,366 & 31 & 44 & 75 \\
\hline
\end{tabular}

The cervices which appeared normal with intact epithelium numbered 1,499 , and those with benign erosions 1,389, and the numbers of unsuspected cancers were 18 and 16 respectively. Although this is admittedly a small series there does not seem to be any significant difference between the two main groups of cervices, the unsuspected cancers being distributed almost equally between eroded and normal cervices.

\section{Treatment and Follow-up}

There were 31 in-situ cancers in the group (28 unsuspected and 3 from the suspect group), and they have been treated in three ways-namely, total abdominal hysterectomy with small vaginal cuff, vaginal hysterectomy, and conization biopsy followed by cauterization. Nine patients were treated by conization and cautery only, and seven are being followed by regular cytological checks, which are normal so far, the remaining two having defaulted. Twenty-two patients were treated by hysterectomy, 14 abdominal and 8 vaginal, and of these, 12 showed persistence of in-situ cancer in the hysterectomy specimens, despite prior conization biopsy, and in one vaginal hysterectomy the abnormal epithelium extended over the ectocervix to within $12 \mathrm{~mm}$. of the cut vaginal edge.

\section{Widespread In-situ Cancer with Vaginal Involvement}

In addition to the patient mentioned above who showed in-situ cancer involving the whole cervix to within $12 \mathrm{~mm}$. of the cut edge at the fornices, two patients with in-situ cancer who were not screened by cytology are thought to be worth reporting as the lesions covered the whole cervix and upper part of the vagina.

The first patient, aged 33, had a biopsy before the cytology programme began, and a cytological follow-up was requested. The smears showed numerous malignant cells persisting, and a Wertheim hysterectomy was done. Although not the usual treatment for what is thought to be an in-situ lesion, in this case it was fortunate, as microscopic invasion was noted just outside the original biopsy area and the in-situ lesion extended over the cervix, fornices, and upper third of the vagina, terminating just short of the cut edge. She has been followed for five years and there is no evidence of further vaginal involvement so far.

The second patient, also aged 33, had a biopsy which showed a very well-differentiated in-situ cancer. Followup smears continued to show atypical cells and after a year were frankly malignant. The patient was a reluctant attender and was persuaded with difficulty to have further treatment. A total hysterectomy with small vaginal cuff was done, and the histology showed 
an invasive cancer $8 \mathrm{~mm}$. in diameter on the lateral aspect of the cervix close to the fornix, the outermost edge being only $250 \mathrm{~m} \mu$ from the line of incision, while the in-situ changes continued to the cut edge. There was practically no macroscopic evidence of the invasive cancer, and even if another biopsy had been taken before hysterectomy it would have been unlikely to include the area so close to the fornix, and the diagnosis would still have been of in-situ cancer. This patient was given radiotherapy and remains well. Greene and Peckham (1954) reported a very similar case of a welldifferentiated in-situ cancer found to be invasive after one year.

\section{Comment}

These widespread lesions are not common, but have been reported on a number of occasions (Harvey, 1958 ; Meigs, 1958 ; Mussey and Soule, 1959 ; Te Linde, 1959; Parker et al., 1960), and when unrecognized at the time of hysterectomy have been responsible for the later development of invasive cancer of the upper vagina in some patients. All these writers stress the need for careful follow-up of all hysterectomies for early cancer in order to discover and treat these lesions, and $\mathrm{Te}$ Linde also suggested using Schiller's test to discover the extent of the lesion before operation.

As it would be of considerable advantage to patient and gynaecologist if the existence of such widespread lesions were diagnosed before hysterectomy to avoid the possibility of cutting through and leaving behind part of the lesion in the vagina, it is suggested as an alternative to or in addition to Schiller's test that smears from the fornices and junction of upper and middle thirds of the vagina be taken at the time of biopsy in patients with positive cytology.

With the patient anaesthetized and in the lithotomy position good exposure of the vaginal vault is obtained, and after douching the vagina thoroughly with normal saline to remove any exfoliated cells which might give rise to error, the vagina is mopped dry very gently and the smears are taken. For the first smear the spatula is swept round the fornices, care being taken to avoid touching the cervix. Using a fresh spatula, a second smear is taken right round the vagina about the junction of upper and middle thirds, and after this the biopsy is taken. This procedure has been followed for most of the patients with positive out-patient cytology since 1958 , and only two have shown suspicious cells in the fornix smears. One had an unsuspected early invasive cancer and would not have had any treatment at all but for the positive cytology findings in her out-patient smear, and the other was the patient mentioned earlier who had an in-situ lesion extending to within $12 \mathrm{~mm}$. of the cut vaginal edge after vaginal hysterectomy.

This is a very simple way of obtaining information on the extent of the lesion, and it is reasonably accurate. The gynaecologist may then be presented with the maximum amount of information, enabling him to decide the best treatment for each individual patient.

If removal of the lesion is incomplete and is discovered later, as either in-situ or invasive cancer of the vagina, it cannot be called a recurrence, as it has been present all along. Careful examination of the vaginal cuff should be done in all cases where the uterus is removed for in-situ cancer of the cervix to make certain that all the abnormal epithelium has been removed and that treatment has been adequate.

\section{Discussion}

A great deal has been written about cytology and early cancer in the past ten to fifteen years, and this is only a small series to add to the list, but the results agree with much of the published information. Incidence rates in themselves I would not regard as important, and it has been demonstrated that they can vary with the ages of the patients screened. Therefore, before discussing the subject, information regarding agegroups screened is necessary for comparing the rates. What is important is that cytology can find more of these early cancers at a stage when they are curable than any other method at present available. The majority of in-situ cancers are found in the 20-44 age-group (see Table III), and, because of this, cytology should be part of the routine examination at all post-natal as well as all gynaecological clinics. Overall attendance at postnatal clinics is generally low, but the general practitioner (S.E. Scotland Faculty, C.G.P., 1958) is in a unique position in that there must be few women whom he could not see for a post-natal examination. In this way almost all patients at risk could be covered without the need for special clinics or large screening programmes.

High parity does not appear to have an influence on the development of in-situ or invasive cancer, and in this series more of the cancer patients were of low than of high parity (see Table IV). It is not suggested that the lower the parity the more the likelihood of cancer. and the explanation is probably that there are more small than large families now. This is confirmed by a report by Mack (1962), who estimated that in Scotland in 1959 the proportion of families with four to five children was about $13 \%$, and that of those with six or more about $5 \%$. It would be most unwise to confine any screening programme to patients of para 4 and over.

Erosion of the cervix has long been regarded with suspicion by gynaecologists and thought to be associated with the later development of cancer, and no doubt thorough treatment of many erosions has led incidentally to the treatment of some in-situ cancers ; but among the patients in this series the unsuspected cancers were found equally distributed between the eroded and the apparently healthy cervices (see Table V). From these findings it does not seem as if cancer had any particular preference for the eroded cervix.

The average age of the in-situ group compared with that of the invasive group shows a 15.5-year difference between the diagnosis of in-situ cancer and that of clinically recognizable cancer, and age differences varying from 10 to 17 years have been reported (Te Linde, 1959 ; Boyes et al., 1962). In Table III the agegroup incidence showed a marked drop in the number of in-situ cancers found after 44 years, but all the unsuspected invasive cancers were in the over-44 agegroup. The drop in the number of in-situ lesions at this age coupled with the appearance of unsuspected invasive cancer supports the view that in-situ cancer does progress to invasion, and that the whole process from in-situ to clinically obvious cancer may take many years. When one considers that a five-year "cure" is a good result for invasive cancer diagnosed clinically, regardless of clinical staging, and that many patients die before achieving it, it is evident that when a cancer becomes recognizable clinically the patient is in the later stages of the disease. From the evidence accumulating she has had her in-situ cancer followed by progressive and silent invasion for 10 to 20 years, during which period a simple 
smear could probably have discovered it, and at a time when treatment, although undramatic, is effective. When the cancer is left to manifest itself clinically the patient has to undergo sometimes heroic treatment in an effort to achieve the possibility of a five-year cure.

Although cytology could find the vast majority of these early lesions little has so far been done to establish a cytology service, and until its use is as routine in gynaecological and post-natal clinics as is the taking of blood tests in antenatal clinics, women will continue to present in out-patient departments in the late phase of the disease with its consequent high mortality.

Cancer of the cervix must now be regarded largely as a preventable disease, and, with the remedy in our own hands, surely few can fail to be impressed with the urgency of the problem presented to us.

\section{Summary}

The results of a trial survey covering 3,366 women attending a gynaecological clinic are given. Thirty-five unsuspected cancers ( 28 in-situ and 7 invasive) were found, an incidence of $1.04 \%$.

The in-situ cancers were almost all found in patients under 45 years, while the 7 unsuspected invasive cancers were found in those over 45 .

An average age difference of 15.5 years between the diagnosis of in-situ cancer and the appearance of clinically obvious cancer is reported.

High parity had no influence on the cancers in this series.

The clinical appearance of the cervix of all the women screened was noted and about one-half were found to be eroded, while the unsuspected cancers were almost equally distributed between the eroded and healthy cervices.
Of 22 patients who had hysterectomy for in-situ cancer of the cervix after diagnostic conization biopsy, 12 had in-situ cancer persisting in the hysterectomy specimen, and a scrupulous follow-up of those treated by biopsy only is advised.

Three patients with widespread in-situ cancer of the cervix, two of whom had vaginal involvement and were later found to have invasive cancer of the cervix, are reported, and it is urged that vaginal involvement should be looked for before hysterectomy for in-situ cancer of the cervix.

I would like to thank Dr. W. A. Horne for giving permission and technical help for this work and the technicians who did all the staining of the smears. I am indebted to Professor Ian Donald for his interest and encouragement, and to his staff for their co-operation, also the University Department of Pathology for permission to see the relevant histology.

\section{REFERENCES}

Anderson, A. F., Grant, M. P. S., and McBryde, R. M. (1951) Proc. roy. Soc. Med., 44, 308 .

Brit and Cockburn, M. K. (1953). J. Obstet. Gynaec. Brit.

Ayre, J. E. (1947), Amer.J. Obstet. Gynec., 53, 609

Boyes, D. A., Fidler, H. K., and Lock, D. R. (1962). Brit. med. J., 1, 203.

Greene, R. R., and Peckham, B. M. (1954). Amer. J. Obstet. Gynec., 67, 883.

Harvey, C. M. (1958). Ibid., 76, 807.

Mack, J. A. (1962). Stevenson Lecturer in Citizenship, Glasgow University.

Meigs, J. V. (1958). Amer. J. Obstet. Gynec., 76, 807 (in discussion).

Mussey, E., and Soule, E. H. (1959). Ibid., 77, 957.

Papanicolaou, G. N., and Traut, H. F. (1943). Diagnosis of Uterine Cancer by the Vaginal Smear. Commonwealth Fund, London, Oxford, New York

Parker, R. T., et al. (1960). Amer. J. Obstet. Gynec., 80, 693.

South-east Scotland Faculty of the College of General Practitioners (1958). Lancet, $2,895$.

Te Linde, R. W. (1959). Amer. J. Obstet. Gynec., 78, 1071.

\title{
SURgical CAPSUle OF THE BENIGN ENLARgEMENT OF THE PROSTATE ITS DEVELOPMENT AND ACTION
}

\author{
BY
}

\author{
J. E. SEMPLE, M.D., F.R.C.S. \\ Surgeon, St. Paul's Hospital; Consulting Urologist, Watford and District Peace Memorial Hospital
}

\section{[With Special Plate]}

The term "surgical capsule" is applied to the fibromuscular covering of the hypertrophied lobes of the benign enlargement of the prostate; it separates the hypertrophied periurethral glands from the glands of the posterior lobe. It therefore occupies precisely the same position as the interlobar or periurethral septum, which is described as separating the periurethral glands from those of the posterior lobe. The existence and structure of this septum and its relation to the surgical capsule have given rise to this investigation.

\section{Material}

Post-mortem specimens were obtained of the whole gland, including the base of the bladder, for nearly every year of life from puberty to old age. A series of foetal and infantile glands were also sectioned. Whole sections of enucleated glands were examined. A total of 107 glands were included in this series. Each gland was sectioned at the upper extremity of the verumontanum in the horizontal plane and four sections were cut. Some specimens were also cut sagittally and coronally and a few diagonal to the sagittal plane. In cases of special interest step sections were cut at various levels. The four sections were stained respectively with haematoxylin and eosin, van Gieson, Weigert's elastic stain, and Masson's triple-dye stain. The sections were examined by means of an Aldis microprojector fitted to an Aldis projector. Two drawings were made of each specimen-one in black-and-white, the other in colourseparate colours being used for different tissues and structures.

\section{Review of Literature}

The majority of writers have accepted that the surgical capsule is the normal outer coat of a benign neoplasm and that enucleation takes place between this layer and the compressed glandular tissue of the posterior lobe. Marion (1940) states that the capsule completely surrounds the adenomatous tissue, the fibres of which are arranged in a circular manner around the tumour, varying in thickness from 2 to $5 \mathrm{~mm}$. From the interior of the capsule he describes muscle fibres branching off to surround the enclosed nodules of the 